\title{
Investigación-creación desde la comunicación. Posibilidades del arte en la hiperesfera'
}

\section{Research-creation from communication. Possibilities of art in the hypersphere}

https://doi.org/10.18566/comunica.n46.a07

\section{Resumen}

El presente trabajo muestra la aparición de la hiperesfera, entendida como el entorno digital en el cual el arte habría de tener una participación especial que lo vincula a otros modos de asir la realidad. En el contexto de la revisión de la investigación-creación como método emergente para la producción de conocimiento, este explora algunas experiencias significativas de la vanguardia reciente para mostrar cómo estas obras evidencian un nuevo escenario donde las fronteras entre arte, comunicación y conocimiento se desplazan hacia lugares emergentes. El propósito es sondear algunas de las características comunes que unen arte y comunicación en el contexto de la hiperesfera, y, de manera particular, sus implicaciones para las aspiraciones científicas del campo de estudio de la comunicación.

\section{Abstract}

This article seeks to show the emergence of the hypersphere, understood as the digital environment in which art should have a special participation that links it to other ways of grasping reality. In the context of the review of research-creation as an emerging method for knowledge production, this work reviews some significant experiences of the recent avant-garde to show how these works evidence a new scenario where the boundaries between art, communication and knowledge move to emerging places. The purpose is to probe some of the common characteristics that unite art and communication in the context of the hypersphere, and, in particular, its implications for the scientific aspirations of the field of communication studies. 


\section{Introducción}

Una de las ideas más fuertes que atraviesan lo contemporáneo es, sin duda, el concepto de convergencia (Borges Rey, 2010; Scolari, 2015). Esta, que debe entenderse no solo en términos de los dispositivos cuyos lenguajes ahora pueden interactuar, sino también como una plataforma de redimensionamiento de lo comunicacional mismo, presenta un amplio conjunto de características, de las cuales una es central para la discusión que acá comenzamos: la capacidad de eliminar las distancias; una característica que se ha convertido, en virtud de lo digital, en el hecho innegable de la difuminación de los límites.

No hablamos solo de los límites físicos, cuya eliminación tanto inspiraba a los teóricos (integrados) de los años 90 (Gil Calvo, 2003). Hablamos de la consistencia, las texturas, la comprensión misma de la experiencia de la vida social.

En efecto, si la Modernidad (sólida, como acuñó Bauman [2015]) se caracterizó por el intento férreo de mantener, vía la razón, cada cosa en su lugar, la Contemporaneidad (hipermoderna, según Lipovetsky [Lipovetsky y Charles, 2006]; líquida, según Bauman [2015]) insiste en no conformarse con las clásicas divisiones, estructuras, lógicas y modos de hacer las cosas. Pero no es que no las tenga; de hecho, parte de la tarea que ahora nos compete a quienes investigamos la comunicación es señalar, una y otra vez, que (en los entornos digitales) convergentes y transmediáticos también hay divisiones, estructuras, lógicas, narrativas y modos de hacer. Y que la tarea consiste en descifrarlos.

Lo que pasa es que una de las características de nuestra forma de relacionarnos como humanos con los entornos que habitamos es, justamente, nuestra incapacidad de ver y entender en qué consisten las tesituras de ese entorno (Roncallo-Dow, 2011b). No es una particularidad de esta época convergente; ya en la Modernidad fue necesaria una ciencia que hiciera visible ese entorno: "La economía es un modo particular de hacer visibles las cosas" (Berardi, 2017, p. 129).

En ese marco, reflexionar las mediosferas como entornos tecnológicos, esto es, como averiguaciones epistémicas en el contexto de experimentaciones estéticas, surge como una tarea relevante en el contexto particular de la convergencia mediática, en clave digital. Particularmente, procuramos entender cómo con la hiperesfera surge un escenario en el que aparecen nuevos matices a la idea de investigación-creación. comunicación

número 46

Enero-junio

2022

Arte, Hiperesfera, Investigación-creación, Comunicación.

\section{Key words}

Art, Hypersphere, Researchcreation, Communication. 
Para fundar esta discusión, proponemos un acercamiento en cuatro estaciones. En primer lugar, una mirada breve al concepto de investigacióncreación, el cual ha traído una renovación de la discusión sobre el lugar del arte en la sociedad y, de manera muy particular, a su posible injerencia en la producción de nuevo conocimiento. Allí, de especial interés, será discutir el lugar que la comunicación como campo de estudios pueda tener en dicho concepto. En segundo lugar, miraremos la configuración de la idea de hiperesfera. En tercer lugar, revisaremos algunas experiencias hiperesféricas que, a nuestro modo de ver, resultan significativas en lo relacionado con nuestro objeto de reflexión. En cuarto lugar, sacaremos unas derivas que, según entendemos, son las que más comprometen ese encuentro del arte con lo digital, lo digital con la comunicación y la comunicación con la investigación-creación.

\section{Investigación-creación}

En Colombia, el concepto de investigación apareció como fruto de una larga discusión de las facultades de artes, arquitectura y diseño por obtener del Estado el reconocimiento de sus modos de saber, generar reflexión y producir conocimiento. La discusión, que se rastrea desde 2008 (Secretaría de Cultura y Deporte, 2013), logró que en 2013 se generara la inclusión de productos artísticos y de diseño en la plataforma de registro de productos de investigación del aplicativo CVLac, encargado de registrar la producción de los investigadores en Colombia. Este dispositivo, administrado por Colciencias (ahora MinCiencias), ente regulador de la investigación en el país, es una muestra de cómo los dominios de saber son, como lo recalcó Foucault $(2000,2017)$, dominios de poder.

La intensa discusión, que en versiones posteriores del modelo permitió el paso del simple registro a su puntuación dentro de la medición realizada por la entidad, convocó a profesionales del arte, la arquitectura y el diseño a reflexionar sobre la relación entre la creación y la investigación. Sin embargo, la comunicación encontró allí posibilidades interesantes para el reconocimiento de productos típicamente asociados a la profesión (documentales, fotografias, trabajos periodísticos), que antes no lograban un lugar en la plataforma.

Lo interesante del asunto es cómo, al final, no se trató únicamente de abrir espacio para el registro y posterior medición de los productos, sino, ante todo, una pregunta por la naturaleza científica de la comunicación, las condiciones intrínsecas de sus formas de generar conocimiento y, de rebote, las fronteras cada vez menos claras entre el arte y la comunicación. En esto, 
facultades de artes, diseño y arquitectura encontraron una situación similar a las facultades de comunicación.

En esa y ponemos énfasis. La conjunción, que antes separaba dos dominios del saber-hacer plenamente distinguibles entre sí (el arte y la comunicación), ahora, en virtud de eso que genéricamente hemos denominado convergencia, se torna confusa (Calle, 2013).

No pretendemos hacer una historia del concepto, labor que Casas (2013) ya adelantó, ni una revisión de los dominios semánticos que envuelve la investigación-creación, tarea que ya Alba y Buenaventura (2020) realizaron. Nos interesa señalar cómo la comunicación se ha insertado en una discusión liderada por facultades de otras áreas del saber, asunto en el que no acusamos una suerte de apropiación, sino que nos parece sintomático de eso que con Louise Merzeau (1998) denominamos hiperesfera.

Es una experiencia habitual para cualquier universitario en Colombia que los estudiantes de Comunicación suelen ser los menos convencionales en sus formas de hablar, vestir y relacionarse en una ciudadela universitaria. Salvo si en esta existen, digamos, programas de artes visuales, plásticas o escénicas. La observación empírica corrobora lo que por otros lados no es tan fácil de dirimir: ¿dónde se encuentran el arte y la comunicación?

Las posturas más convencionales señalan que mientras el arte gira en torno a la autoexpresión, la comunicación pone su mirada en el otro. La distinción, útil para las pedagogías del esclarecimiento y la diferenciación, se hace menos clara no solo en el día a día de profesionales del arte y la comunicación, sino en aquello que en los actuales entornos mediáticos se puede comprobar.

Ahora bien, ¿dónde queda la investigación-creación en este contexto? Como sugerimos antes, esta aparece como un asunto institucional de reivindicación de las formas de generación de conocimiento. En efecto, como lo recalcan Alba y Buenaventura (2020), sin el asunto institucional, que implica presupuestos, registros y certificaciones, este tema no tendría lugar. Pero, además de ello, la discusión de fondo señala cómo tradicionalmente el arte, el diseño y la comunicación habían sido consideradas como áreas funcionales o expresivas, donde la mirada subjetiva se asumía como óbice de la construcción de conocimiento, cosa que el positivismo y la Modernidad elevaron a condición de única fórmula para construir verdad, con el previo sacrificio de la subjetividad (Arias, 2010).

El advenimiento de la convergencia digital, sin embargo, nos sume en otro escenario, otro entorno técnico y mediático. Uno en el cual la 
realidad física, análoga o como se la quiera llamar, es hipermediada por signos, representaciones digitales de la realidad. Esto ha implicado el desplazamiento progresivo de la experiencia empírica de los sujetos en el mundo (fisico) hacia una serie de interacciones en las que esa experiencia fisica no solo queda relegada a un segundo lugar, sino que determina lo que luego serán las experiencias físicas en tanto tales.

El asunto se agrava cuando los entornos digitales, que creaban mundos virtuales con cierta independencia de los mundos reales (como en el videojuego, por ejemplo), entran a interactuar de una manera menos discreta y más continua: se pierden las fronteras que atajaban un mundo allá y otro acá (Baricco, 2018). Sin esa interafectación, fenómenos visibles como las protestas sociales en clave de Primavera Árabe no serían posibles (El Hamdouni, 2013).

Pero, de nuevo buscando un fondo, repliega las distancias entre quienes tenían derecho a autoexpresarse (tradicionalmente, las personas del arte) y los ciudadanos (digitales) del común. Ellos (o sea, nosotros) ahora pueden construir relatos de vida, fundar negocios o construir medios informativos sin las aduanas que antes había que pagar (tradicionalmente, el ostentar títulos que los legitimaban para tal ejercicio).

No se puede caer en la fantasía democraticista (Gil Calvo, 2003). Por el contrario, hay que mantener activas las alarmas, pues ese entorno convergente, como señalamos, también tiene sus dueños y, sobre todo, está siendo operado por corporaciones cuyos intereses son claros (Smicek, 2014).

Esa convergencia entre usos técnicos, ciudadanos, profesionales y autoexpresivos es la que reclama otros lugares para lo que se considera conocimiento relevante y para las formas en que este se puede producir.

Así que la discusión estratégica sobre la investigación-creación, que en lo práctico permite registrar productos de conocimiento que no son artículos en revistas científicas o patentes, se hace posible también porque el entorno mediático en el que vivimos hoy es uno en el cual las fronteras entre procesos sociales, instituciones y sujetos se movilizan, y pasan a ocupar lugares difusos. Difusos, claro está, si los acotamos dentro de los marcos comprensivos de antes.

Ahora bien, en esa relación entre entornos (esferas) habitados y los procesos sociales que alli podemos vivir, el arte ha tenido convencionalmente la misión de incomodar, de expandir fronteras perceptivas y, desde allí, configurar nuevos modos de lectura. Es lo que mostraremos a continuación. 


\section{Hiperesfera}

Las relaciones entre lenguaje y técnica, así como sus modulaciones en el arte, han sido materia de consideración en años recientes, luego de que durante siglos se los viera como instancias plenamente diferenciables. En los inicios del arte, es incluso dificil hablar de actividad propiamente artística (Debray, 1994), pues los artefactos no se construían como una finalidad en ellos mismos, sino como resultado de otras mediaciones sociales (Longo, 2009). Por tanto, el tránsito entre artesanía y arte puede ser equiparable al salto entre técnica y tecnología, cambio de tesitura que supondría no solo un saber (técnica), sino un poder dar razón de ese saber (tecnología) (Roncallo-Dow, 2012).

Para Levy (2007), la presencia de ese logos que complejiza el hacer y lo lleva a un dar razón del mismo ocurre por el lenguaje: "Ese mismo hombre quien habla, entierra a sus muertos y talla el sílex" (2007, p. 5). En ese sentido, las técnicas son imaginadas, fabricadas y reinterpretadas, mediante su uso intensivo como útiles que constituyen lo humano. Hablar de la técnica es, entonces, hablar de dispositivos que afectan la configuración social de los grupos en los cuales aquella se aplica, pero que la afectan no como algo externo, sino como algo interno.

Es decir, que el dar razón no llega como un momento posterior, lo cual exige salirse de la mirada que procura departamentos estancos que se suceden linealmente. Más bien, supone pensar en capas, sustratos de sentido que se interafectan. Al decir de Taylor (2018), esto se puede apreciar en los momentos en que el lenguaje se constituye como clave de lo humano: la mímesis, el símbolo y lo teórico; en lo primero, el lenguaje imita el entorno, en lo simbólico lo abstrae y en lo teórico vuelve tautológicamente sobre sí.

Querríamos insistir en dos asuntos clave. Primero, la imposibilidad de trazar una periodización con cortes sobre la relación lenguaje-técnica-tecnología; segundo, la necesidad de ampliar la idea de lenguaje como tecnología de la palabra. Como sistema que permite el reemplazo de cosas del mundo por signos, el lenguaje está imbricado en la técnica, por cuanto la labor de la técnica es, precisamente, reemplazar la acción directa del cuerpo sobre el mundo mediante metáforas.

Así las cosas, en el tamiz de las representaciones construidas debería asumirse como una toma de distancia cognitiva, en la cual el ser humano pone signos donde antes puso su cuerpo. Pero esos signos no salen para quedarse objetivados externamente en los dispositivos; por el contrario, vuelven al ser humano, modifican su percepción, al ampliar unos dominios de realidad mientras opera la reducción de otros. Es a esto a lo que McLuhan 
denominó, apoyado en Benjamin, el sensorium (McLuhan, 1996; RoncalloDow, 2011a). Pronto volveremos sobre esto.

Lo que interesa es mirar cómo las posibles periodizaciones lineales deberían ceder lugar a una comprensión más compleja, dinámica e intrincada, donde el ser humano afecta su entorno (mediante signos-dispositivos) y, a su vez, es afectado por este (Roncallo-Dow, 2011a; Uribe-Jongbloed y Roncallo-Dow, 2013). De cara al asunto de la imagen en movimiento, una de las formas de comunicación más empleadas en la actualidad, esta revisión es necesaria.

Para ello, un referente fundamental es el trabajo de André Leroi Gourhan (1971), quien en su libro El gesto y la palabra esboza cómo la técnica y el lenguaje se desplegaron a medida que el hombre prehistórico se erguía del piso, desarrollaba un pulgar oponible y la laringe comenzó a articular sonidos; la suma de estos movimientos precipitó la expansión del cerebro y, con ello, llevó a nuevo nivel la necesidad inherente de comunicar ideas y generar herramientas que con el tiempo se fueron perfeccionando. Así, la transformación de la técnica y los modos de expresión del lenguaje permiten problematizar la actualidad de la imagen en movimiento en el arte.

La consideración de Gourhan es pertinente, pues hace notar que tanto técnica como lenguaje avanzan de la mano; de esta forma, el arte y sus prácticas, entendidas como lenguaje, se han desarrollado a medida que la técnica se transforma: junto con la técnica, los lenguajes artísticos innovan, adaptan, generan y desenvuelven nuevas concepciones respecto a cómo nos relacionamos con el mundo. En pocas palabras, el arte como lenguaje se ha expandido a medida que la técnica avanza.

Debray (1994) esboza una historiografia de la imagen (no lineal y no convencional respecto a la historia positivista) en la cual se refiere a su ejecución (técnica y semiótica). Bajo la noción de mediosferas, concepto que reúne características perceptivas, técnica de ejecución y motivaciones que existen al generar una imagen, Debray propone considerar la logosfera, la grafosfera y la videosfera.

En Debray, la logosfera contiene el momento en el que el mito y la religión imperaban la producción de imágenes regidas por un arquetipo; la grafosfera es el período del genio creador, en el cual nace la noción de arte, el desarrollo del pensamiento liberal y el hombre como centro del mundo, donde el desenvolvimiento de la creación de imágenes estará dado por el prototipo de las tendencias que se incluyen en esta esfera. La videosfera surge cuando la imagen pasa a ser regida por la industria, los intereses económicos, el entretenimiento, la inmediatez y la reproductibilidad en masa, bajo la conducta del estereotipo. 
Cabe anotar que Debray, para poder diferenciar esas tres mediosferas, se aleja de la tendencia lineal historicista que asume los periodos como núcleos cercados; por consiguiente, su diferenciación se obtiene mediante los desarrollos técnicos que han impactado altamente a la sociedad, con los consecuentes cambios en las mentalidades que supone cada desarrollo técnico. Entonces, pone de relieve a la imprenta para dar partida a la grafosfera y punto diferenciador sobre la logosfera; lo mismo ocurrirá con el advenimiento y desarrollo de la imagen televisada como diferenciador y continuación de la grafosfera. Es preciso anotar que Debray (1994) no propone una ruptura brutal entre las tres mediosferas, sino la idea de que ellas se yuxtaponen en el tiempo.

Pero si estas mediosferas delinean vasos comunicantes entre sí, no es menos cierto que la imagen en movimiento, como técnica y como lenguaje del arte, aparece con propiedad en el contexto de videosfera, en la cual Debray (1994) cambia el punto de vista de la imagen aurática a una ya banalizada y capitalizada que fue magnificada gracias al trabajo de los rayos del tubo catódico, las cintas magnéticas y un nuevo ideal social. Esto es, si antes de las tecnologías del cine y la televisión había imagen en movimiento, el desplazamiento clave ocurre en la condición económica de condensación de información propia de lo que algunos autores denominan semiocapitalismo: la generación de intercambios de valor en los que no ocurren transacciones de objetos físicos (Berardi, 2017; Fisher, 2018).

Esa modificación sensorial del mundo por vía de las técnicas, que en McLuhan fundamenta el concepto de galaxia y en Debray surge como mediosfera, permiten arrojar luz sobre las consecuencias que el entorno técnico, del cual los medios integran una parte decisiva, procura sobre las mentalidades. Ágilmente, Debray incorpora la idea de esfera, que nos remite a los conceptos de ambiente, ecosistema o entorno.

El arte no fue ajeno a las nuevas mentalidades que tuvieron lugar a propósito de la adaptación de la imagen analógica: el avance de los dispositivos de grabación que se fueron haciendo livianos en su proceso de desarrollo, la facilidad de reproducción y los precios asequibles, que gestaron una nueva opción aprovechada para la creación de imágenes poniendo de manifiesto un nuevo agregado del discurso del arte, facilitaron el surgimiento del videoarte.

La exploración analógica de los artistas llegó a configurarse en corrientes de video-performances, video-instalaciones, video-esculturas, expanded cinema, etcétera, y, como consecuencia, el video adquirió una competencia para exponer conceptos complejos que fueron dificiles en su representación y que encontraron su nicho en el videoarte (Roncallo-Dow, 2005, 2013). Se configuró así una nueva técnica para la exploración desde 
la interdisciplinariedad, las tecnologías dadas al avance de los años y la expresión artística puesta ahora en espacios de exhibición (Granés, 2012; Sloterdijk, 2012).

Si bien el desarrollo del videoarte ha tenido un amplio estudio y es un vivo ejemplo del quiebre técnico de una mediosfera a otra (lo cual se ajusta a los cambios en las mentalidades sociales fijadas en la era de la videosfera), más que centrar el análisis en su fenomenología e historiografía propias, interesa destacarlo como campo de exploración de técnicas, expresividades y códigos de comunicación que han saltado a campos de la industria como el videoclip (Roncallo-Dow y Uribe-Jongbloed, 2017; Sedeño-Valdellós, 2002; Sedeño-Valdellós, 2007), el cine de masas (Martel, 2011; Ortiz Morales, 2010) y los conciertos de música (Zunzunegui Díez, 1989).

La interconectividad propia de la era digital, como se avizoraba en el disperso campo del videoarte, genera lo que, ampliando la lectura de Debray, Merzeau (1998) nombra hiperesfera. Al respecto, Cuervo comenta:

Se encuentran las redes, los hipermedios, el hiperespacio, los electrones, los hologramas, las simulaciones, lo virtual, el Internet, el avatar, la adaptabilidad y la conexión, entre otras. En resumen, la hiperesfera se define por el re-equilibrio de prácticas e instrumentos alrededor del modo del hipertexto y la red (2016, p. 198).

El boom de las pantallas múltiples, el hecho irrefutable de que hoy día la mayoría de las personas pueden tener una pantalla en su bolsillo; la posibilidad de interactuar con la imagen continuamente, la conectividad, la información a alta velocidad; la apertura de fronteras y la realidad expandida...: todo, en suma, hace que el entorno social y cultural adquiera nuevas formas para la expresión, la dominación, el consumo y el relacionamiento entre los individuos. Así, "cada ideología tiene un índice de desarrollo mediológico que le es propio y hace parte de la mediosfera a la que pertenece" (Cuervo, 2016, p. 200). Ello da cuenta del traslape entre la videosfera y la hiperesfera, de una hegemonía de lo analógico a lo digital, de las comunicaciones por pulsos a la conexión en red y de una realidad de las pantallas singulares (cine y televisión) a una inmersión multiplataforma que propone una hiperrealidad. Ya lo vaticinaban Lipovetsky y Serroy:

El homo sapiens se ha vuelto homo pantalicus; hoy nace, vive, trabaja, ama, se divierte, viaja, envejece y muere rodeado de pantallas que lo muestran cuando es feto, en las ecografias, que desde los primeros meses le ofrecen televisión especialmente concebida para bebés, que le proponen encontrar su alma gemela o compañía de una noche en foros de contactos y que llegan a proponerle que elija su ataúd y su modelo de tumba, si lo desea, consultando 
sitios web apropiados y tramitando el pedido. La economía, la sociedad, la cultura, la vida cotidiana, todas las esferas sufren la remodelación de las tecnologías de la información y la comunicación (2009, p. 85).

Habitar en la era de los datos, de la información instantánea y de nuevas propuestas de realidad fomentadas por los nuevos dispositivos de la comunicación (los smartphones, la realidad virtual y la web 4.0) conduce a un viraje en los modos de uso del lenguaje (Danesi, 2008). Alli, el arte, como dispositivo semiótico, no ha sido ajeno a estos cambios de técnicas y formas expresivas. Es así como surge también un arte aplicado a las pantallas inmersivas, la realidad virtual, la interactividad y la realidad expandida. De tal suerte que ya no solo es necesario un análisis de la imagen en movimiento, sino también del movimiento con la imagen: en cuanto estos nuevos dispositivos tecnológicos proponen una interacción corporal para su apropiación, las posibilidades aumentan y, con ellas, la necesidad de reflexionarlas.

\section{Arte en la hiperesfera}

Desde la mirada de la hiperesfera se abordarán algunos proyectos artísticos audiovisuales que se insertan en estas nuevas tendencias técnicas, junto con los cambios y adaptaciones del sensorium.

Son numerosos los proyectos que se podrían considerar por su aplicación de conceptos, técnicas o áreas de experiencia propios de la hiperesfera; campos como artnet, arte electrónico, mappings, live stream y hologramas, entre otros, resaltan por ser utilizados como territorios en construcción de experiencias novedosas. Para efectos de centrar el estudio, se analizarán tres posibilidades del arte que integra la imagen en movimiento en una actualidad dada a la hiperesfera: documental interactivo, realidad virtual y realidad aumentada.

\section{Documental interactivo (1)}

Como clasificación general, Levy (2007) afirma que hay dos tipos de mundos virtuales: los limitados o editorializados (es decir, cerrados, como CD-ROM o instalaciones), y que denomina off-line, y los que son accesibles en red, indefinidamente abiertos a la interacción y sometidos a la transformación por parte de los usuarios (abiertos, on-line) (2007, p. 118).

El documental interactivo podría considerarse como una nueva modalidad narrativa que surgió de la convergencia entre el entorno digital y el cine documental, con lo cual sería un híbrido entre lo que propone Levy. Este tipo de productos aportan y adoptan diferentes formalizaciones en función 
de los medios que utilizan y los lenguajes que intervienen. Un reto para el creador-director de la pieza es ofrecer un amplio panorama en cuanto a la diversidad de los componentes que entran a interactuar en una obra, con el fin de generar una experiencia interesante durante la navegación a través de los diferentes contenidos. A esto se suma la necesidad de poseer una conciencia de la interacción, ya que se propone que en esta modalidad documental el interactor genere múltiples realidades subjetivas; por esta razón, el realizador de una obra interactiva debe ser consciente de que, por ser una obra de carácter abierto y de libre elección, la experiencia narrativa puede tomar diversos rumbos, haciendo de la persona que interactúa un cocreador de la pieza.

Entre los precedentes del documental interactivo vale considerar la multimedia y el cine de ensayo. La primera es un sistema que utiliza más de un medio de información, y que puede contener imágenes, sonidos, animaciones y videos. Además, adopta formas de navegación como la lineal (el caso del cine) y la no lineal (que es progresivo a partir de la interacción, como un videojuego). En décadas anteriores, muchos de los casos fueron masificados desde el CD-ROM y la web 2.0. El segundo es una hibridación entre las estructuras del ensayo literario y la narrativa cinematográfica; así comparte mecanismos retóricos, estructurales y de disposición teórica.

El film-ensayo se ubica precisamente a medio camino entre el documental y la vanguardia, y resuelve las limitaciones de ambos: por un lado, dialoga con la realidad, como hace el documental, pero, además, supera el formalismo vanguardista en integrar la mirada del espectador en una forma que lo necesita para completarse (Arnau, 2013, p. 147).

El ensayo cinematográfico se consolida como una reflexión sobre los límites entre realidad y ficción, desde una perspectiva más ontológica que estilística. Como sintesis de ambos, el documental interactivo integra la retórica ensayística, la apropiación del fragmento cinematográfico, la interacción del multimedia y la expresión de contenidos con una amplia gama de reflexión.

Un proyecto documental interactivo notable es Estera: plantas medicinales y resistencia, de la artista colombiana Alexandra Gelis, documental interactivo que, desde la perspectiva de los habitantes de San Basilio de Palenque, establece una conexión con el espectro de los conocimientos tradicionales que existen en esa comunidad, encontrando temas como el uso de las plantas en la medicina, la artesanía, las parteras, etcétera. La obra ofrece una mirada sigilosa y respetuosa de los saberes de la comunidad de San Basilio, en la que resulta de gran relevancia la experiencia interactiva de cara al conocimiento encaminado a la protección y rescate de sus tradiciones y saberes ancestrales. La artista usa varias técnicas para la captura de las 
imágenes, desde el video 8 hasta el video en full HD; así, hay una especie de plasticidad para la construcción de los fragmentos del documental, en el cual es la intención del espectador la que marca el camino.

Imagen 1. Estera: plantas medicinales y resistencia.

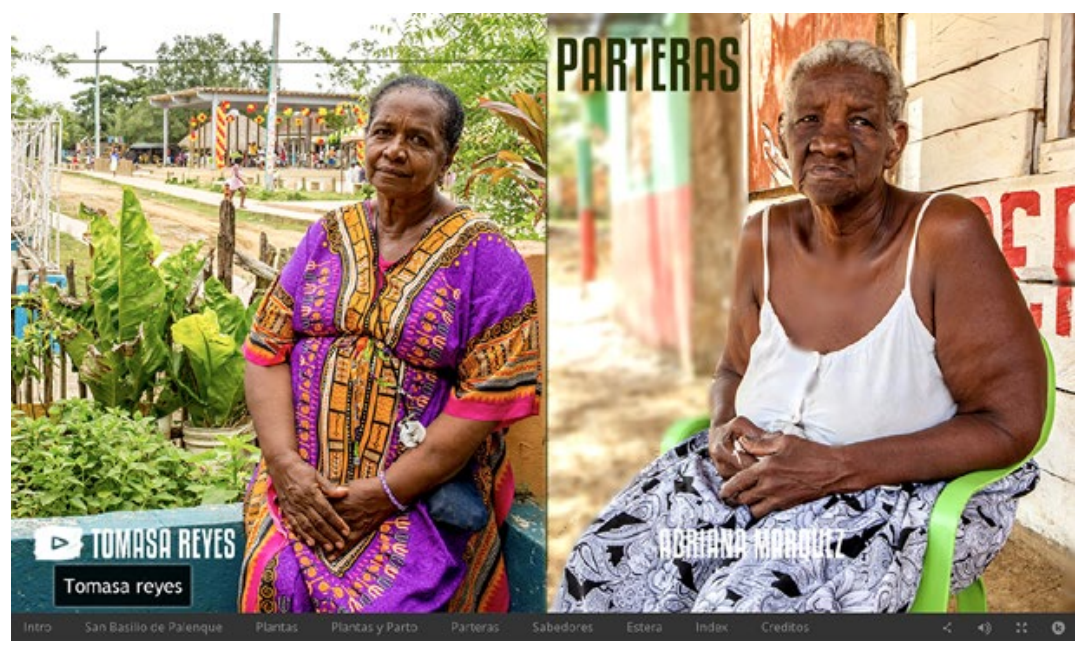

Imagen 2. Estera: plantas medicinales y resistencia.

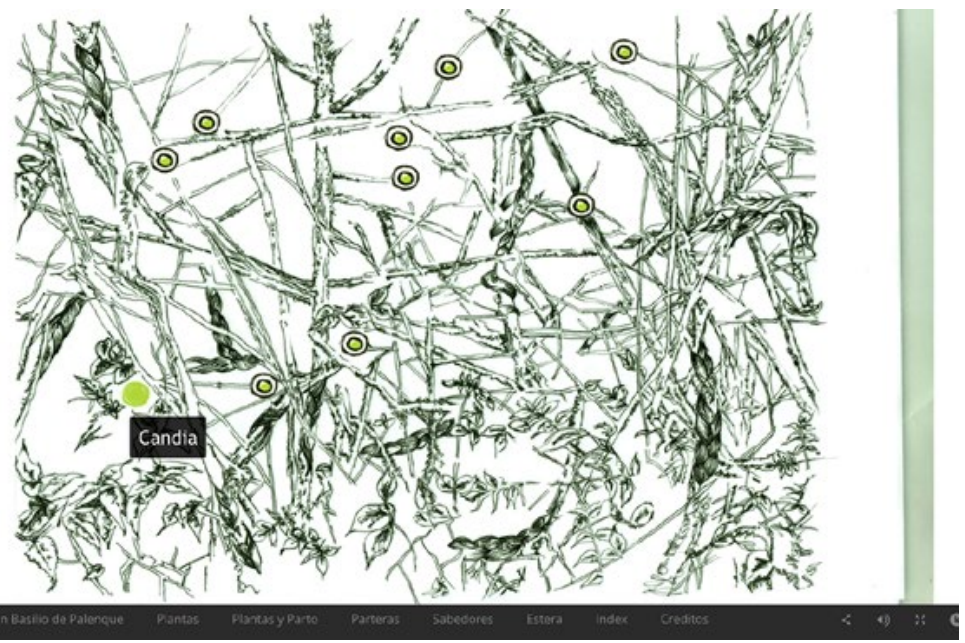

\section{Realidad virtual (2) y realidad aumentada (3)}

Pokemon Go fue la cumbre de la formalización que se venía dando con los avances tecnológicos y el entretenimiento, la mezcla de la realidad y un mundo de ficción (Stremman, 2021). Este juego obliga a sus usuarios mo- 
verse en el espacio fisico y real para encontrar personajes ficticios derivados de una serie de televisión japonesa. La consolidación de las acciones propuestas por este juego entran al ruedo de la crítica sociológica sobre la pérdida de la noción de una realidad fundamental por aquel espacio de ficción, y se separan así las dos realidades por una frontera muy delgada para quien es usuario asiduo del juego o de juegos similares (Baricco, 2018).

Ahora bien, en similar situación y connotación se encuentra la polémica foto hecha en el Mobile World Congress 2016, en la que se observa a Mark Zuckerberg caminar al lado de fanáticos de la tecnología mientras usan dispositivos de realidad virtual sin percatarse de su presencia. Sin duda, la imagen inaugura la nueva condición en la que la atención humana ya no se concentra en entornos reales

Es necesario precisar los términos realidad virtual (RV) y realidad aumentada (RA), que si bien comparten rasgos, se diferencian con respecto a los instrumentos y la experiencia inmersiva que proponen. Tenemos la RV como la que intenta sumergir al usuario en un mundo que está simulado. Como campo de estudio, entonces, trata de indagar la integración de imágenes sobre video procesado de manera digital, lo cual intensifica la percepción de los mundos simulados (Giraldo, 2011).

\section{Imagen 3. Mark Zuckerberg en el Mobile World Congress de Barcelona 2016.}

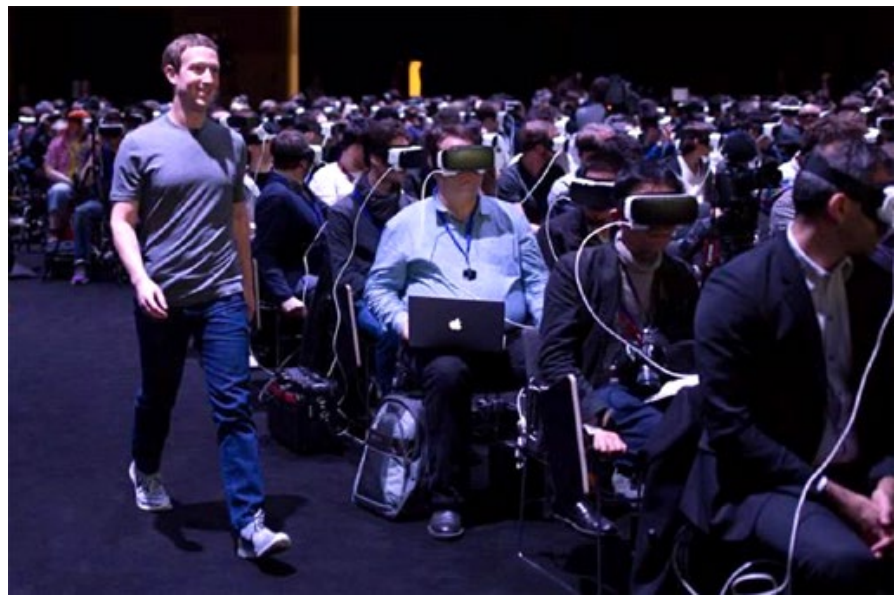

Fuente: Zuckerberg (2016).

La RA, por su parte, está definida como un sistema en el cual se mezclan informaciones reales producidas informáticamente en un entorno físico de manera interactiva y en tiempo real, alineando mundo real y mundo 
simulado (Ruiz Torres, 2016). Esta nueva tecnología, si bien acarrea un sinnúmero de críticas, no deja de ser una herramienta que ya está al servicio de la humanidad, que se consume asiduamente y que cada día se sumerge más en la cotidianidad de las personas.

Existe, entonces, un reto en el sentido de encarar esta tecnología no como vehículo para la alienación del hombre, sino como instrumento para la reflexión, la sensibilidad, la expresión y la toma de conciencia respecto a las verdaderas realidades que se dejan de ver, precisamente, por acción de estos instrumentos.

Entre los múltiples proyectos artísticos dados a la realidad virtual, se encuentra Acute Art, una plataforma para la producción y distribución de obras en RV. En su sitio web se pueden explorar los distintos procesos para la concepción de las obras de RV que acoge: se trata de una visión en la generación de esta nueva posibilidad dentro del arte y un acercamiento a sus procesos de creación. El proyecto también está disponible para su navegación en dispositivos móviles. El aplicativo, que se puede descargar gratuitamente, ofrece la exploración inmersiva de cada uno de los proyectos de los artistas que participan en Acute Art.

\section{Imagen 4. Acute art.}

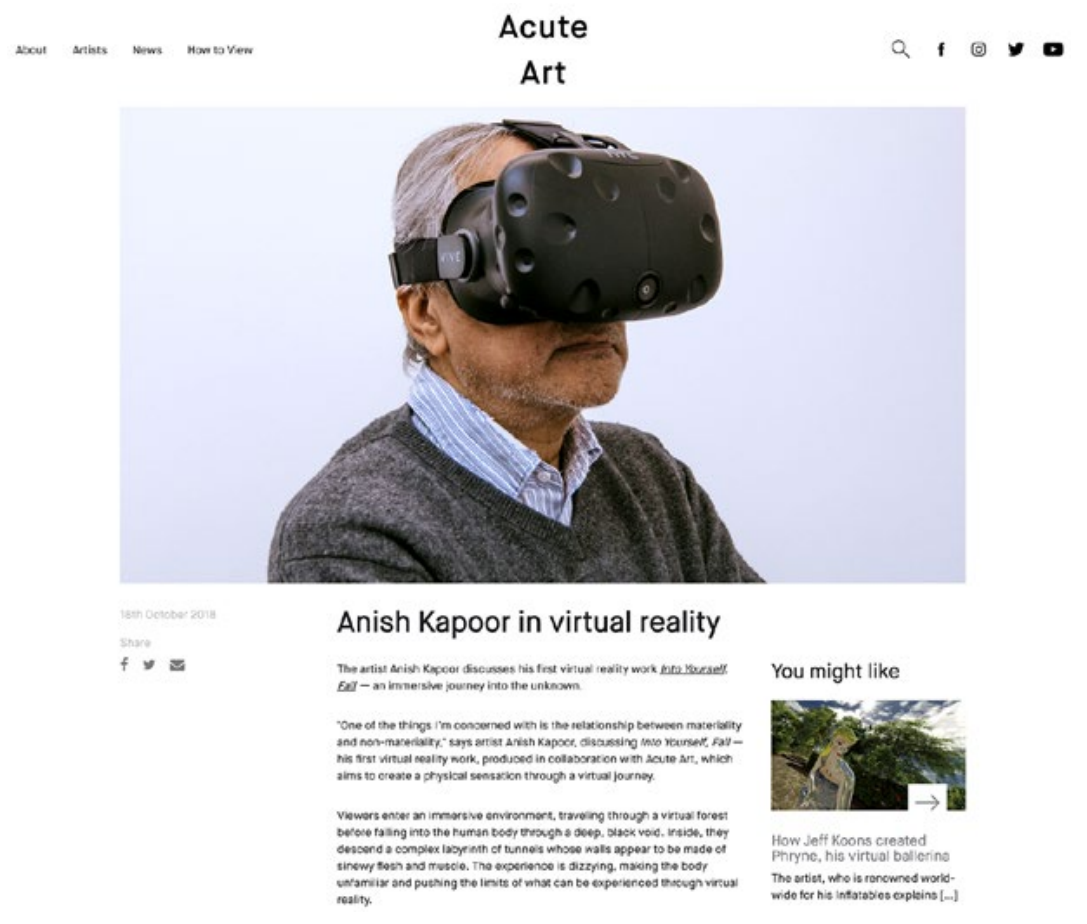


Escif es un artista español que ha desarrollado su obra a partir de estéticas urbanas como el grafiti, siempre inquieto por la ampliación de sus posibilidades estilísticas y con un temario que aborda los aspectos sociales y políticos. Escif encuentra una opción para la expansión de su mensaje social en la RA: el uso técnico expande la experiencia de su obra, además de que genera un pensamiento crítico y consensuado sobre el uso de las tecnologías. Su reciente proyecto, Magic piano, es lo que se podría llamar un oxímoron balanceado. ¿Por qué definirlo así?

El proyecto gira alrededor de la problemática africana sobre la extracción de coltán, que ha llevado a la comunidad del Congo a una guerra civil. La propuesta se formaliza en una instalación musical, interactiva y de realidad aumentada; para formar el oxímoron mencionado, se debe usar la RA por medio de una tablet que, sin duda, ha sido fabricada con componentes de coltán, paradoja intencionada del artista, pues sin ella los personajes pintados sobre una pared no podrían cobrar movimiento para ilustrar sobre esa realidad ni podrían activarse las armonías de piano por acción del interactor (propuesta de un irónico balance).

\section{Imagen 5. Magic piano.}

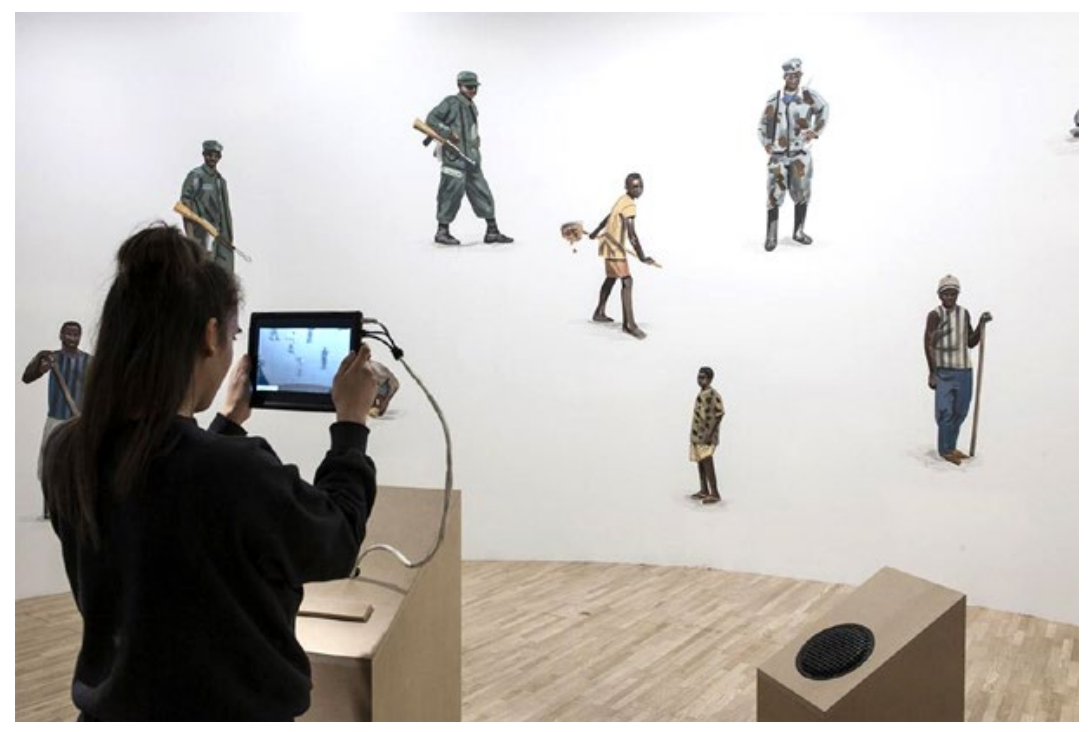

Fuente: Escif (2019).

\section{El campo en la hiperesfera}

Las obras reseñadas nos ponen en un escenario ambivalente, donde el arte explora nuevas aproximaciones entre creadores y usuarios. El documental 
interactivo abre posibilidades al espectador para que navegue sus propias rutas y, desde allí, participe en la coconstrucción de conocimiento. La realidad virtual lo sumerge en un dominio que simula un mundo, mientras la realidad aumentada lo lleva a habitar un mundo posible configurado desde un oximoron.

Las palabras que atraviesan estas obras parecen conocidas: multimedia, realidad virtual, interactividad. Pero no es del todo así. En las tres experiencias, tres desplazamientos semánticos operan diferentes posibilidades de relación entre quien produce la obra, quien la navega y el mundo que se despliega tras ella. Veamos.

El documental interactivo de Gelis convierte la comunidad palenquera en una extensa red de datos: plantas y artesanías devienen moléculas de bytes, y el entorno comunitario surge como un tejido informático denso. Acute Art revela la lógica procesual en el advenimiento del arte: la obra terminada es deconstruida en una trama depurada de procedimientos que la hacen posible, de suerte que el espectador se reencuentra con el detrás de. Escif acusa la eterna contradicción de cada subsistema técnico: para permitirnos aumentar un fragmento del mundo, otro debe abdicar.

Si se miran en perspectiva, estas tres propuestas expanden tres asuntos que son clave en la hiperesfera: el lugar de quien produce el mensaje, el lugar de quien lo navega y el mundo que, como referencia tradicional de los actos de comunicación, da un paso (no sabemos si decir atrás, adelante o a un lado). En últimas, el arte sirve para de-mostrar la fragilidad del mundo haciendo conscientes a los usuarios de cómo este se pierde tras la obra.

De cara a nuestra discusión sobre la investigación-creación, señalamos que arte y comunicación comparten al menos tres características que en estas obras aparecen transversalmente: la no identificación con el positivismo y su visión objetivista, la necesidad de un uso expresivo de la técnica, y la fusión entre objeto, método y proceso.

Primero. La instauración del paradigma positivista implicó la separación entre conocimiento y experiencia (Agamben, 2011). La empresa científica, pese a su reivindicación del empirismo, relegó la experiencia individual a un lugar atómico y molecular. Si antes se conocía mediante la experiencia (de hecho, el arquetipo es el encuentro de un individuo con un universal), el método científico, en la visión positiva, exigió medidas, parámetros e indicadores para validar esa experiencia; es decir, escindió al sujeto generador de conocimiento, lo alienó al pedirle ingresar un registro reticular de su observación e indicarle que este sería válido en la medida que alimentara la matriz paradigmática de la disciplina. 

grafosfera no es tan solo el cambio de un dispositivo de registro lingüístico a uno visual. Es un cambio en la tesitura de la experiencia del mundo. Por tanto, las formas de comunicación se transforman en términos del alcance en lo que se dice, pero también en la naturaleza misma de lo que es decible: la técnica permite imaginar mensajes, y cada técnica sugiere unos dominios semánticos particulares, así mismo en el arte.

Tercero. Mientras la ciencia reclama una clara separación entre el sujeto y el objeto de investigación, y pide pautas precisas de actuación del primero frente al segundo (es decir, un método), en el arte y la comunicación, sujeto, objeto y método están estrechamente involucrados. En arte y comunicación, lo que se dice está permeado por quien lo dice (RoncalloDow y Uribe-Jongbloed, 2013).

Con todo, la hiperesfera es un sistema técnico que genera un entorno digital, vertiginoso y cuyas configuraciones sociales toman la forma de enjambres (Han, 2014); la pregunta por cómo se hace investigación-creación en comunicación tal vez la acerca más a las lógicas del arte que a las de la ciencia en clave positivista. Esto implicaría una toma de postura epistemológica clara, y concluimos que esta es la condición para poder entender cómo y por qué un documental con cámara al hombro, un reportaje en primera persona o una serie de fotografias pudieran (o no) generar conocimiento.

No se trata de la ventaja enorme de que ahora podamos mostrar ante el Estado que nuestros productos audiovisuales, multimediales o escritos también son conocimiento. Se trata de reflexionar a fondo cómo y por qué a través de estos podemos hacernos conscientes, y permitir a otros que también lo sean, del entorno que habitamos. Entorno quiere decir cosas que se pueden semantizar, a la vez zonas oscuras que surgen en virtud de los medios que ahora usamos. Comunicación debería ser ambas caras de la moneda, pero en la medida en que nos vamos volviendo ciegos hacia las formas en que la técnica (cualquiera: el espejo o la moneda, el teléfono u olla a presión) incide en nuestro sensorium, el arte puede ayudarnos en la tarea de recordar cómo es que eso que llamamos mundo (o cultura) se despliega ante nuestra mirada con la sugerencia sutil de que siempre ha sido así.

Investigación-creación podría abrir otros sentidos de esa experiencia, pues "[l]a cultura, y el análisis de la cultura, son valiosos en tanto nos permiten escapar de nosotros mismos" (Fisher, 2018, p. 57): escapar de nosotros mismos vendría a ser investigar el entorno para crear nuevos modos perceptivos. Y tal vez por ese camino-otro nos aproximemos a la ciencia por otras vías: las del arte. 


\section{Referencias}

Acute art. (2018). Acute art.

Agamben, G. (2011). Infancia e historia. Adriana Hidalgo Editora.

Alba, G. y Buenaventura, J. G. (2020). Cruce de caminos. Un estado del arte de la investigación-creación. Cuadernos del Centro de Estudios en Diseño y Comunicación, 79, 21-49.

Arias, J. C. (2010). La investigación en artes: el problema de la escritura y el "método". Cuadernos de Música, Artes Visuales y Artes Escénicas, 5(2), 5-8.

Arnau, G. (2013). El documental interactivo como nuevo género audiovisual: estudio de la aparición del nuevo género, aproximación a su definición y propuesta de taxonomía y de modelo de análisis a efectos de evaluación, diseño y producción. Universidad Pompeu Fabra.

Baricco, A. (2018). The game. Anagrama.

Bauman, Z. (2015). Modernidad líquida. Fondo de Cultura Económica.

Berardi, F. (2017). Fenomenología del fin. Sensibilidad y mutación colectiva. Caja Negra.

Borges Rey, E. (2010). La nueva convergencia de la música digital: imaginarios y prosumo emergente. En M. De Aguilera, A. Sedeño-Valdellós, y E. Borges Rey (Eds.), Hibridando el saber. Investigar en comunicación y música (pp. 90-99). Universidad de Málaga.

Calle, M. (2013). La investigación-creación en el contexto de las prácticas estético-artísticas contemporáneas. Desplazamientos disciplinares y desafíos institucionales. Mediaciones Sociales, 12, 65-79. https://doi.org/https://doi.org/10.5209/rev_MESO.2013.n12.45263

Casas, M. V. (2013). Una aproximación al estado del arte en Colombia y otros países sobre la discusión investigación-creación en artes. Avances y propuestas.

Cuervo, M. (2016). De Prometeo al Cyber Prometeo. Revista Nexus, 20, 188-223. https://doi. org/https://doi.org/10.25100/nc.v0i20.1841

Danesi, M. (2008). The medium is the sign: was McLuhan a semiotician? MediaTropes ejournal, 1, 113-126. www.mediatropes.com

Debray, R. (1994). Vida y muerte de la imagen. Paidós.

El Hamdouni, Y. (2013). Internet y la Primavera Árabe: hacia una nueva percepción del ciberespacio. Paix et Securité Internacionales, 1.

Escif. (2019). Magic piano. http://www.streetagainst.com/2020/03/27/20-magic-pianomima-brussels/

Fisher, M. (2018). Fantasmas de mi vida. Escritos sobre depresión, hauntología y futuros perdidos. Caja Negra.

Foucault, M. (2000). Los anormales. Fondo de Cultura Económica.

Foucault, M. (2017). Discurso y verdad. Sobre el coraje de decirlo todo. Siglo XXI Editores.

Gelis, A. (2015). Estera: plantas medicinales y resistencia.

Gil Calvo, E. (2003). El miedo es el mensaje. Riesgo, incertidumbre y medios de comunicación. Alianza.

Giraldo, A. (2011). "Realidad virtual”: análisis del marco teórico para explorar nuevos modelos de comunicación. Anagramas, 9(18), 93-109.

Granés, C. (2012). El puño invisible. Taurus.

Han, B. C. (2014). En el enjambre. Herder. 
Leroi Gourhan, A. (1971). El gesto y la palabra. Universidad Central de Venezuela.

Levy, P. (2007). Cibercultura. La cultura de la sociedad digital. Anthropos.

Lipovetsky, G. y Charles, S. (2006). Los tiempos hipermodernos. Anagrama.

Lipovetsky, G. y Serroy, J. (2009). La pantalla global. Cultura mediática en la era hipermoderna. Anagrama.

Longo, O. (2009). El universo de los griegos. Actualidad y distancias. Acantilado.

Martel, F. (2011). Cultura mainstream. Cómo nacen los fenómenos de masas. Taurus.

McLuhan, M. (1996). Comprender los medios de comunicación. Las extensiones del ser humano. Paidós.

Merzeau, L. (1998). Ceci ne tuera pas cela. Cahiers de Médiologie, 6, 27-39.

Ortiz Morales, J. M. (2010). El synchrociné o ciné-pupitre de Charles de la Commune: un dispositivo olvidado. En M. De Aguilera, A. Sedeño-Valdellós, y E. Borges Rey (Eds.), Hibridando el saber. Investigar en comunicación y música (pp. 179-189). Universidad de Málaga.

Roncallo-Dow, S. (2005). El video (arte) o el grado lego de la imagen. Signo y Pensamiento, 24(47), 135-149.

Roncallo-Dow, S. (2011a). Más allá del espejo retrovisor. La noción de medio en Marshall McLuhan. Editorial Pontificia Universidad Javeriana.

Roncallo-Dow, S. (2011b). Medios, antimedios, sondas y clichés. Revisitando a Marshall McLuhan, el explorador. Signo y Pensamiento, 31(59), 122-138.

Roncallo-Dow, S. (2012). Técnica, tecno-logía: más allá de la sinonimia y la objetualidad. Universitas Philosophica, 29(58), 39-65.

Roncallo-Dow, S. (2013). Video, videoarte, iconoclasmo. Cuadernos de Música, Artes Visuales y Artes Escénicas, 8(1), 103-125.

Roncallo-Dow, S. y Uribe-Jongbloed, E. (2013). La investigación en comunicación. Los límites y limitantes del conocimiento. Co-herencia, 10(18), 161-187.

Roncallo-Dow, S. y Uribe-Jongbloed, E. (2017). La estética de los videoclips: propuesta metodológica para la caracterización de los productos audiovisuales musicales. Cuadernos de Música, Artes Visuales y Artes Escénicas, 12(1), 79-109. https:/ /doi.org/ https://doi.org/10.11144/Javeriana.mavae12-1.evpm

Ruiz Torres, D. (2016). Medios de comunicación impresos y realidad aumentada, una asociación con futuro. Intervención, 3(5), 39-44.

Scolari, C. (2015). Ecología de los medios. Entornos, evoluciones e interpretaciones. Gedisa.

Secretaría de Cultura y Deporte. (2013). El arte como productor de conocimiento.

Sedeño-Valdellós, A. (2002). Música e imagen: aproximación a la historia del video musical. Área Abierta, 3, 2-11.

Sedeño-Valdellós, A. (2007). El videoclip como mercanarrativa. Revista Sigma, 16, 493-504. Sloterdijk, P. (2012). Has de cambiar tu vida. Pre-Textos.

Smicek, N. (2014). Capitalismo de plataformas. Caja Negra.

Stremman, E. (2021). Crossover literacies: a study of seventh graders' multimodal representations in texts about Pokemon Go. Computers and Composition, 59, 102-129. https://doi.org/https://doi.org/10.1016/j.compcom.2021.102629

Taylor, C. (2018). Animal de lenguaje. RIALP. 
127
comunicación
número 46
Enero-junio
2022

Uribe-Jongbloed, E. y Roncallo-Dow, S. (2013). El medio es el mito: entre McLuhan y Barthes. Universitas Philosophica, 30(61), 177-203.

Zuckerberg, M. (2016). Mark Zuckerberg en el Mobile World Congress de Barcelona 2016 [Foto] [Actualización de estado]. Facebook. https://www.

facebook.com/zuck. https://scontent.feoh3-1.fna.fbcdn.net/v/t31.0-

8/12719113_10102665120179591_3471165635858509622_0.jpg

Zunzunegui Díez, S. (1989). Pensar la imagen. Cátedra. 